\title{
Mathematics and Philosophy
}

\author{
Klara Fatkullinovna Gabdrakhmanova \\ Department of Information Technologies, Mathematics and \\ Natural Sciences \\ Ufa State Petroleum Technological University, \\ Branch of the University in the City of Oktyabrsky \\ Oktyabrsky, Republic of Bashkortostan, Russia \\ klara47@mail.ru
}

\author{
Liliya Zakarievna Samigullina \\ Department of Humanities and Socio-Economic Sciences \\ Ufa State Petroleum Technological University, \\ Branch of the University in the City of Oktyabrsky \\ Oktyabrsky, Republic of Bashkortostan, Russia \\ sliliyaz@mail.ru
}

\author{
Gulnara Rishadovna Izmaylova \\ Department of Oil and Gas Field Exploration and Development \\ Branch of the University in the City of Oktyabrsky \\ Oktyabrsky, Republic of Bashkortostan, Russia \\ gulena-86@mail.ru
}

\begin{abstract}
The article considers mathematics as a way of teaching reasoning in symbolic non-verbal communication. Particular attention is paid to mathematical ways of thinking when studying the nature and its worldview. The nature is studied through the theory of experimental approval of scientific concepts of algorithmic and nonalgorithmic "computing". Various discoveries are analyzed and the role of mathematics in the worldview is substantiated. The greatest value of mathematics is development of knowledge in order to express it in abstract language of mathematics and natural science, i.e., to move to the meta-pedagogical level of understanding of problems and tasks.
\end{abstract}

Keywords - languages of mathematics, mathematical reality, information science, cyber world.

\section{INTRODUCTION}

The article discusses the use of mathematical reality and computer science for studying and explaining nature. In our desire to understand the structure of evolutionary processes of the world (in its physical, economic, and social manifestations), we are driven by curiosity and the desire to know how to improve our lives through the study and exploitation of natural resources.

The development of mathematics and the expansion of its application have shown that in the material world there are a number of objects and relations whose mathematical description is not reduced to quantitative relations and dimensional forms. The role of such structures as equivalence, order, closeness, family, etc. was revealed. At the same time, it is clear that such structures equally manifest themselves in various areas of science. It turned out that along with structures that directly reflect real-world objects and relationships, many applications require higher-level abstractions.

The role of mathematics in the natural sciences, humanities and social sciences is that it offers general and clear models for the study of surrounding realities, in contrast to the more vague qualitative models characteristic of the premathematical stage of development of this science.

\section{PROBLEM STATEMENT}

Computer science and computational mathematics play a central role in the analysis of tools for predicting and controlling physical, economic, and social phenomena. Computer technology has advanced as an effective means of information processing. The great computing power has contributed to the discovery of many unexpected facts about our world, its structure and evolutionary processes.

These discoveries brought us to a new level of understanding of depths of the universe - from the "microscales" (microparticles) of the mysterious microcosm to the evolutionary processes of life and consciousness, from the level of social systems - to the vast scales of space and time. Therefore, philosophical criticism of the ideas of cumulative development of modern mathematics, as well as the rapid change in computer technology and the crisis of ideas of mathematical education can be considered as prerequisites for the transition of mathematical science to a new quality.

The study of complex problems of modern science and technology is impossible without building models of the world phenomena. The manifestation of such models in any field of science and technology, a separate industry, shows that the system of concepts has reached the level of mathematical abstraction, i.e., mathematics is indispensable. While natural science discoveries still reveal unknown properties of the world around them, mathematical discoveries help to detect previously unknown properties of the models of the world and make it possible to create new models.

\section{RESEARCH QUESTIONS}

Philosophical criticism of the idea of cumulative development of modern mathematics, as well as rapid development of computer technology and the associated crisis 
of mathematical ideas can be considered as a prerequisite for the transition of mathematics to a new level. Is it possible to consider philosophical criticism of the idea of combined development of modern mathematics and rapid changes in computer technology and the associated crisis of ideas of mathematical education as prerequisites for the transition of mathematical science to a new level?

\section{PURPOSE OF THE STUDY}

The development of mathematics and expansion of its applications have proved that in the material world there are objects and relations whose mathematical description cannot be reduced to quantitative relations and dimensional forms. At the same time, it is clear that such structures manifest themselves equally in various fields. It turned out further that along with structures reflecting objects and relationships, many applications of mathematical science require higherlevel abstractions.

The purpose of this study is to specify the role of mathematics in general models for studying reality in contrast to the vaguer qualitative models that are characteristic of the pre-mathematical stage of development of this science and objective reality as a whole. Our goal is also to show how mathematics enters the modern world as a method to compensate for the imperfection of our senses and a method for expanding knowledge that a person is able to gain about the world.

\section{RESEARCH METHODS}

To specify applications of mathematical reality and computational informatics, their relationship with the following phenomena the following aspects were studied:

1. Cyber world. Information technology and life;

2. Mathematics and society;

3. The role of mathematics in world cognition;

4. The mathematical theory of computability.

\section{FINDINGS}

\section{Cyber world. Information technology and life.}

The Information Revolution began during the vibrant, prosperous, and successful era of electronics in the 1940s. Theoretical and technological developments in natural sciences of information and communication coincided with the conclusions of Claude Shannon (Bell Telephone Laboratories) drawn about fifty-five years ago [1-3].

Intensive research and technological development, error detection and correction, cryptography and information compression inspired scientists to new discoveries in the field of data processing, communication, cognitive potential, knowledge engineering, as well as artificial intelligence. Recently, the information revolution has put forward new paradigms, new conceptual frameworks and measures with the discovery of sciences of "chaos" and "fractals".

In particular, the science of information, along with physical and mathematical sciences, offers new concepts and tools for research areas that consider (often metaphysical) questions about space and time, life and consciousness, the role of man in this world.

\section{Mathematics and society}

The discovery of new scientific concepts and abstract ideas introduce a new scientific aspect, and an unpredictable effect into our life, psychology and social behavior [4]. For example, when Isaac Newton discovered the classical laws of gravity and motion, he created the theory of classical mechanics that accelerated the industrial revolution of the 19th century. The radical social, economic and psychological changes as a stream of scientific and technological progress in mechanics, thermodynamics, etc., unleashed political forces that ultimately overthrew the feudal dynasties of Europe and promoted modern democratic societies.

Two hundred years after, James Clerk Maxwell opened the electric age in the Western world (the mid-1860s). The application of electromagnetic forces created a new civilization of electrical and electronic means and devices, such as radio, household appliances, television, microwave, computer electronics, laser and many other "miracles".

On June 10, 1854, Georg Bernhard Riemann delivered his famous lecture "On the hypotheses underlying geometry" at the faculty of the University of Göttingen in Germany. He "knocked down" pillars of classical Greek geometry. His discoveries successfully withstood the attacks of skeptics for two millennia. The old Euclidean geometry, in which all geometric figures were considered as two- or threedimensional, collapsed, and a new geometry emerged from its ruins.

The Riemann revolution was of great importance for the future of art and science. Less than three decades after his report, the "mysterious fourth dimension" had an impact on the development of science, philosophy and literature in Europe. Six decades after Riemann's speech, Einstein used four-dimensional Riemannian geometry to explain the origin of the Universe and its evolution. 130 years after, physicists turned to ten-dimensional geometry trying to unite all the laws of the physical Universe. According to Riemann, in multidimensional space, physical laws are simplified [5-10].

The great artists of the 20th century such as Pablo Picasso and Salvatore Dawali, realized the Riemman-message about hyperspace long before. Only years later, scientists began to use multidimensional spaces in changing applications, allowing themselves to "see the invisible and imagine the unimaginable." In fact, we see that the principles of mathematical thinking are applicable to art and linguistics (Samigullina, 2015)

More recently, in the mid-1940s, Einstein's discovery of the mathematical relationship of equivalence between energy and mass led to the "curbing" of nuclear forces turned the world upside down due to the emergence and a subsequent threat of the use of weapons of mass destruction.

We point out the wider psychological, social and economic consequences that may arise as a result of technological exploitation of great achievements of scientific abstract ideas 
and theories, such as those expressed in language of mathematics.

\section{The role of mathematics in world cognition}

Nowadays, scientists study principles of functioning of the human brain. However, the fact that possibility of programming a digital computer, development of the mathematical theory of computability provided a new way of thinking, revealed new approaches to the study of the human brain.

Recently, with the development of a deeper understanding of the subject "calculation", the "old", the Cartesian distinction between the brain and the mind loses its authority. The traditional view of "brain" as a physical organ and "mind" as a ghostly, functional, inconsequential, exclusively subjective "nothingness" studied by psychiatrists, philosophers, and theologians, is disappearing.

Today, a deeper understanding of the concept "computing" allows formulating complex problems that relate to the functions of the mind and matter of consciousness, exploring the role of man in the general evolutionary scenario of our universe. We strive to understand psychic functions of memory, thinking, and consciousness.

Mathematics is the doctrine of general forms characteristic of real life; it creates constantly developing theories that are suitable for many different problems of natural science, technology, and technology. It allows applying mathematical methods in solving problems of one science to completely dissimilar problems of other sciences.

We become more and more convinced that the mechanistic approach to the world does not take place, and we are trying to find the meaning inherent in our Universe. If nature can be considered as a computational process, it is necessary to determine computational limits of the physical world, as well as the nature of physical laws: "If the universe functions like a computer, what are the computational limits of our physical world? Why do we think the laws of nature are mathematical? Let us answer the question about the nature of "reality of mathematics." "Why are the laws of nature mathematical?"

\section{The mathematical theory of computability}

The remarkable success of mathematics in the description of the laws of structure, function, and functional capabilities of our physical world requires explanation. This is often taken for granted that this is the law of the world." When we go beyond observation and direct perception, we try to understand our world by applying logic and rational thinking. We often struggle with some ideas that are difficult to understand through simple visualization. Abstract mathematics is often preceded by a lengthy simulation of a physical phenomenon. The works by great mathematicians are great works of art that describe the idea of eternal and deep reality of our World.

Today, a deep understanding of the concept "computation" and new tools of "computational mathematics" allow formulating complex problems that relate to the functions of the mind and matter of consciousness, and exploring the role of man in the general evolutionary scenario of our universe. We strive to understand the psychic functions of memory, thinking, and consciousness. We are more and more convinced that the mechanistic approach to world simply does not take place when we try to find the inherent meaning in our developing universe.

If nature can be considered as a computational process, it is necessary to determine computational limits of the physical world, as well as the nature of physical laws: "If the universe works like a computer, what are the computational limits of our physical world? Why do we think that the laws of nature are mathematical?"

In physical research and observation, we strive to discover simple laws, concise algorithms that explain complex physical phenomena. In mathematics, we are searching for simple universal rules, in computer science - for compact programs that can be used in various computing situations, even for very complex calculations. As we all know, however, not all mathematical operations can be reduced to simple rules. Not all mathematical operations can be performed using procedures and computer programs that are less complex than the operations themselves. There are mathematical operations that are so complex in nature that they cannot be calculated using any computer program [11-16].

\section{CONCLUSION}

The idea of algorithmic compression was developed in 1960 by Andrei Kolmogorov (USSR) and Ray Solomonoff and Gregory Chaitin (USA) within "algorithmic information theory". They tried to develop a computer program that can describe a mathematical object or a physical system. Exciting facts were discovered when explaining the theory of "random sequences" and "random events" in the physical world, as well as the almost mystical "Omega Number". "Is it possible that the Universe as a whole is described by one program, which is much simpler than the Universe itself?" "Is our universe algorithmically compressible?"

The construction of models of any specific or general scientific areas of mathematical science begins with abstraction. The process of abstraction has its own characteristic features, and in many respects it differs from similar processes in other sciences, since abstraction methods depend on the nature of objects being studied, as well as on nature and goals of their research

The greatest value of mathematics is development of knowledge in order to express it in abstract language of mathematics and natural sciences, i.e. to move to the metapedagogical level of understanding. The prospects for further research are philosophical issues of teaching mathematics, regarding those multicultural processes in society. The most important direction of the research is substantive changes in general educational and pedagogical standards of mathematical education, value guidelines in teaching mathematics.

In all the areas of science, cognition is carried out by abstracting knowable things, objects. In mathematics, understanding is carried out through the construction of 
perfect, accurate models, closely related to abstraction. The construction of models of mathematical science begins with abstraction. The process of abstraction has its own characteristic features, and it is different from the similar process in other sciences, since the methods of abstraction depend on the nature of objects being studied, the nature and goals of their study

In the modern period of development of mathematics, it has become an applied science for natural, economic, social and other sciences. Therefore, mathematical abstraction as a method plays a special role in the system of sciences. This nature of abstraction serves to understand reality. We can say that each mathematical concept contains specific features of abstraction - it can be in the form of symbolism or in the form of words, sentences or statements containing basic properties of things, concepts that are considered an object of understanding.

\section{References}

[1] L. E. J. Brouwer, "Consciousness, philosophy, and mathematics." In Philosophy and Foundations of Mathematics, North-Holland. 1975 pp. 480-494

[2] K. F. Gabdrakhmanova, G. R. Izmailova, E. R. Vasilyeva, "E-learning Environment as a Means for a Modern Engineer Training." In International Scientific Conference "Far East Con" vol. 47 pp. 245-247 October 2018 (ISCFEC, p. 576, 2018).

[3] M. Colyvan, "Applying inconsistent mathematics". In New waves in philosophy of mathematics Palgrave Macmillan, London pp. 160-172. 2009

[4] O. V. Danilova, "Peculiarities of Forming General Cultural Competences in Students of Institutions of Higher Technical Education by Means of Interdisciplinary Integration," SHS Web of Conferences vol. 50, p 1-5, October 2018, (CILDIAH-2018,2018).

[5] A. Y. Polyakov, "Full-fledged level of physical training of a specialist is an integral part of stability of a work process," SHS Web of Conferences vol. 50, p. 1-3. October 2018 (CILDIAH-2018, 2018).
[6] E. R. Vasilyeva, I. M. Sinagatullin, "Regional and ethnocultural specifics for developing intercultural and lingua-cultural competences: the pedagogical strategy,'SHS Web of Conferences vol. 50, p. 1-4, October 2018.( EDP Sciences, 2018).

[7] V.V. Mukhametshin, R.R. Kadyrov, "Influence of nanoadditives on mechanical and isolating properties of cement-based compositions," Nanotechnologies in Construction, vol. 9, No. 6, pp. 18-36, 2017. DOI: 10.15828/2075-8545-2017-9-6-18-36.6.

[8] E. R. Vasilyeva, A. R. Nurutdinova,. "The academic model of managing integration processes: study case of the multicultural educational space" SHS Web of Conferences. vol. 50, p. 71- (FRED 2019, 2019).

[9] V.E. Andreev, A.P. Chizhov, Yu.A. Kotenev, Sh.Kh. Sultanov, V.Sh. Mukhametshin, and A.V. Chibisov, "Prediction of Gas Exposure in the Conditions of the Oil Fields of the Volga-Urals," Atlantis Highlights in Material Sciences and Technology vol. 1, pp. 666-669. August 2019 (ISEES 2019, 2019), .DOI: 10.2991/isees-19.2019.132.

[10] R M Shaidullina, A F Amirov, V S Muhametshin and K T Tyncherov, "Designing Economic Socialization System in the Educational Process of Technological University," European Journal of Contemporary Education, vol. 6 (1), pp. 149-158 2017 DOI: 10.13187/ejced.2017.1.149

[11] L. Z. Samigullina "Some Aspects if Cognitive and Ideographic Characteristics as a Means if Professional Terminological System Description". European Research Studies, vol. 18(4), pp. 197. 2015

[12] R. J. Sternberg, "What is mathematical thinking. The nature of mathematical thinking" pp. 303-318. 1996

[13] G. Weil, "The structure of mathematics. Advances in Mathematical Sciences", vol. 31 (4 (190), 1976, pp. 220-238.

[14] H. Wang, From Mathematics to Philosophy (Routledge Revivals). Phil. Trans. Roy. Soc. London, vol. A247, pp. 529-551, April 1955.

[15] L.S. Kuleshova and V.V. Mukhametshin, "Estimation of the wells hydrodynamic drag level based on wells geophysical survey data" Atlantis Highlights in Material Sciences and Technology vol. 1, pp. 727-729, August 2019. (Symposium "Engineering and Earth Sciences: Applied and Fundamental Research" dedicated to the 85th anniversary of H.I. Ibragimov, 2019), DOI: 10.2991/isees-19.2019.145.

[16] R. I. Suleimanov, M. S. Gabdrakhimov, M. Y. Khabibullin, L. M. Zaripova, E. R. Vasilyeva, "The study of hydraulic hammer device in drilling tool assembly in hydraulical rotary drilling," Int. J. of Engineering and Technology,vol. 7(2), pp. 28-30 2018. 